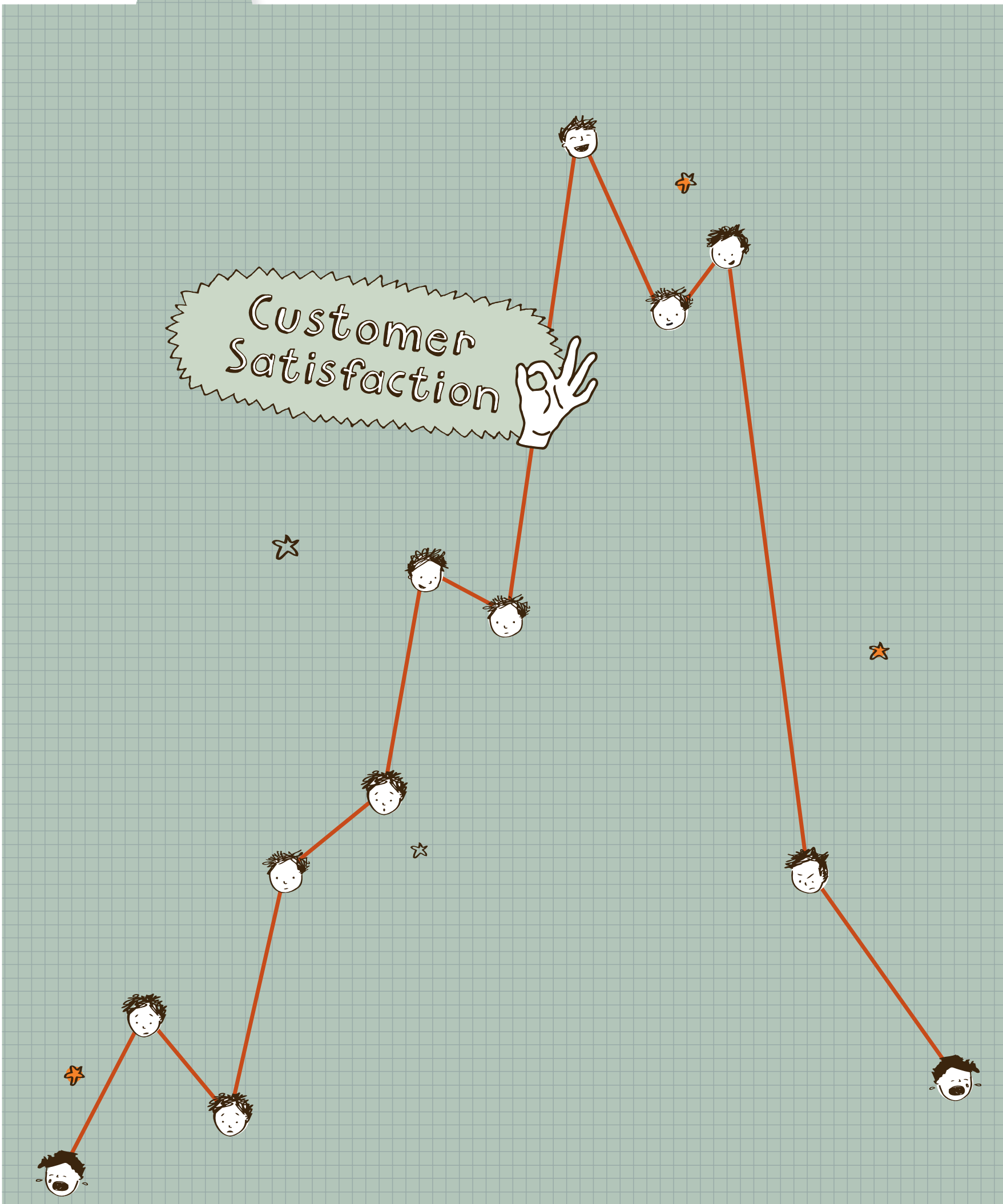




\title{
DOES CUSTOMER SATISFACTION LEAD TO AN INCREASED FIRM VALUE?
}

\author{
Aksoy Lerzan, Bruce Cooil, Christopher Groening, Timothy L. Keiningham \\ and Atakan Yalcin
}

\begin{abstract}
Does customer satisfaction really lead to increased firm value? Traditionally, most financial valuation models do not include customer-related metrics such as customer satisfaction in the process. Studies in marketing, on the other hand, have consistently found that customer satisfaction improves the ability to predict future cash flows, long-term financial measures, stock performance, and shareholder value. This research examines the impact that customer satisfaction has on firm value by employing valuation models borrowed directly from the practice of finance. The data used in the analysis is compiled by merging publicly available customer satisfaction data from the ACSI (American Customer Satisfaction Index) with financial data from COMPUSTAT, and Center for Research in Securities Prices between 1996 and 2006. The results indicate that a portfolio of stocks consisting of firms with high levels and positive changes in customer satisfaction will outperform lower satisfaction portfolios along with Standard \& Poor's 500... Customer satisfaction does matter!
\end{abstract}

The Role of Customer Satisfaction in Creating Firm Value

The stock market is traditionally seen as the barometer that signals how a company is performing and the promise it holds for the future. But recently U.S. firms' earnings have become much less correlated with stock prices. Why has this happened? This phenomenon has been attributed to the failure of analysts to account for intangible assets of a firm. While it is easy and relatively simple to estimate the value added of tangible assets such as plant and equipment, intangible assets such as brand names, patents and technological expertise are just more difficult to value.

Difficulty in valuation of intangibles, however is not the sole reason for its exclusion. Why have analysts historically resisted including information about customer satisfaction into firm valuation models?
Analysts tend to believe that consumer attitudinal data provides little additional information beyond what is contained in other commonly used data sources to forecast performance. Additionally, a focus on improved customer satisfaction requires a longer-term perspective. Investors, however, tend to be driven by short-term performance. Furthermore, chief executive officers (CEOs) are forced to focus on the short-run due to the limited time they have on the job. A recent study of 476 of the world's largest public and private companies found that almost half of all CEOs had held their positions for fewer than three years, with approximately two-thirds holding the position for fewer than five years. CEOs therefore have less time to prove themselves and secure future employment.

Despite this focus on the short-term by managers and investors, there is a growing appreciation that a large part of the market value of firms today is attributable to intangible assets. The market-to-book ratio for Fortune 500 companies averages 3.5 , suggesting that more than $70 \%$ of the market value of the Fortune 500 firms derives from their intangible assets. In fact, the magnitude of intangible assets in today's economy and estimated capitalized value of intangible assets is estimated to be in excess of $\$ 6$ trillion.

Why is customer satisfaction likely to have a positive impact on a company's value? Well how much does it cost a company when its customers are not happy with the product they just purchased....with the level of service they received...when their questions go unanswered... when their order had to be returned?

The answer is that lowered customer satisfaction ultimately damages the value of a company's most valuable asset: its customers. A great deal of research demonstrates that happy customers tend to be better customers. For example, customer satisfaction has been found

\section{THE AUTHORS}

Aksoy Lerzan, Associate Professor, Fordham University N.Y. aksoy@fordham.edu

Bruce Cooil,

The Dean Samual B. and Evelyn R. Richmond Professor of Management, Owen Graduate School of Management, Vanderbilt University, Nashville (TN)

bruce.cooil@owen.vanderbilt.edu

Christopher Groening, Assistant Professor Marketing, Trulaske College of Business, University of Missouri, Columbia (MO) groeningc@missouri.edu

Timothy L. Keiningham, Global Chief Strategy Officer and Executive Vice President IPSOS Loyalty tim.keiningham@ipsos-na.com

Atakan Yalcin, Assistant Professor of Finance, College of Administrative Sciences and Economics, Koc University, Istanbul atyalcin@ku.edu.tr

The article is adapted with permission from the Journal of Marketing, published by the American Marketing Association: Aksoy Lerzan, Bruce Cooil, Christopher Groening, Timothy L. Keiningham and Atakan Yalcin, "The Long-Term Stock Market Valuation of Customer Satisfaction", Vol. 72, July 2008, pp. $105-122$. 
to have a positive effect on customer retention, share of spending, increased receptiveness to cross-selling efforts, reduced complaints, and referrals. This in turn translates into increased cash flows, reduced cash flow variability, and greater buzz about the company.

\section{Data Sources and Approach}

To understand the impact of customer satisfaction on firm performance, we investigated the relationship between customer satisfaction information and a company's stock performance. We tracked customer satisfaction using a national barometer called the American Customer Satisfaction Index (ACSI), developed by the University of Michigan. This ACSI measures customer satisfaction for 43 industries, and more than 200 companies and federal or local government agencies. These companies are broadly representative of the U.S. economy serving U.S. households. We then appended the monthly stock market returns for each of the publicly traded firms in the ACSI sample. The period in this study covers the third quarter of 1996 through the first quarter of 2006 with a total of 151 unique firms.

We examine both the absolute level in customer satisfaction and the changes in customer satisfaction over time by forming portfolios of companies based on a company's customer satisfaction performance over time. Specifically, we devised a classification scheme for portfolios where each firm is allocated into one of the four groups depicted in Figure 1 (Refer to Figure 1).
As new data is released from the ACSI each quarter, firms are then reclassified based upon the new information. This resulted in 117 monthly value weighted portfolio returns from December 1996 to August 2006. This large, robust data set offered us the opportunity to investigate the impact that customer satisfaction has on shareholder wealth by examining the monthly series of the four portfolio returns.

\section{Performance Differences Based on Customer Satisfaction}

How much is $\$ 100$ that is invested in a high customer satisfaction portfolio likely to bring in 10 years? A lot! An investment of $\$ 100$ in Portfolio High at the beginning of December 1996 more than triples to $\$ 312$ by August 2006. If we compare this to the S\&P 500 index, our $\$ 100$ only grows to $\$ 205$. And low satisfaction results in a dismal market performance. An investment of $\$ 100$ in Portfolio Low decreases to $\$ 98$ by the end of the 10 year investment horizon (See Figure 2).

Does this mean that stocks of firms with high customer satisfaction perform better than expected? An analyst might question the results as a function of risk. This is because high risk is associated with higher returns, without necessarily implying abnormal returns.

To address whether customer satisfaction truly creates shareholder value, we turn our focus on excess (or abnormal) returns. This allows us to understand whether the returns generated are indeed due to higher returns rather than accepting high-risk investment strategies. To this end we used three popular valuation models frequently used in finance: the Captial Asset Pricing Model (CAPM), the Fama French 3 Factor Model, and the Fama French (Carhart) 4 Factor Model.

CAPM is a very popular (albeit controversial) model in investment markets and project evaluations. It is widely believed that CAPM does not work well, especially in certain situations such as when using cross sectional data. It does, however, tend to have a more positive reputation in models where time series data are used. CAPM predicts a positive linear relation between an asset's expected rate of return and its covariance risk with the market.

More recently the Fama French 3 Factor Model has gained increased popularity. It is a model that is empirically driven (although it is sometimes criticized for being non-theoretical). It is very popular in financial valuation. 


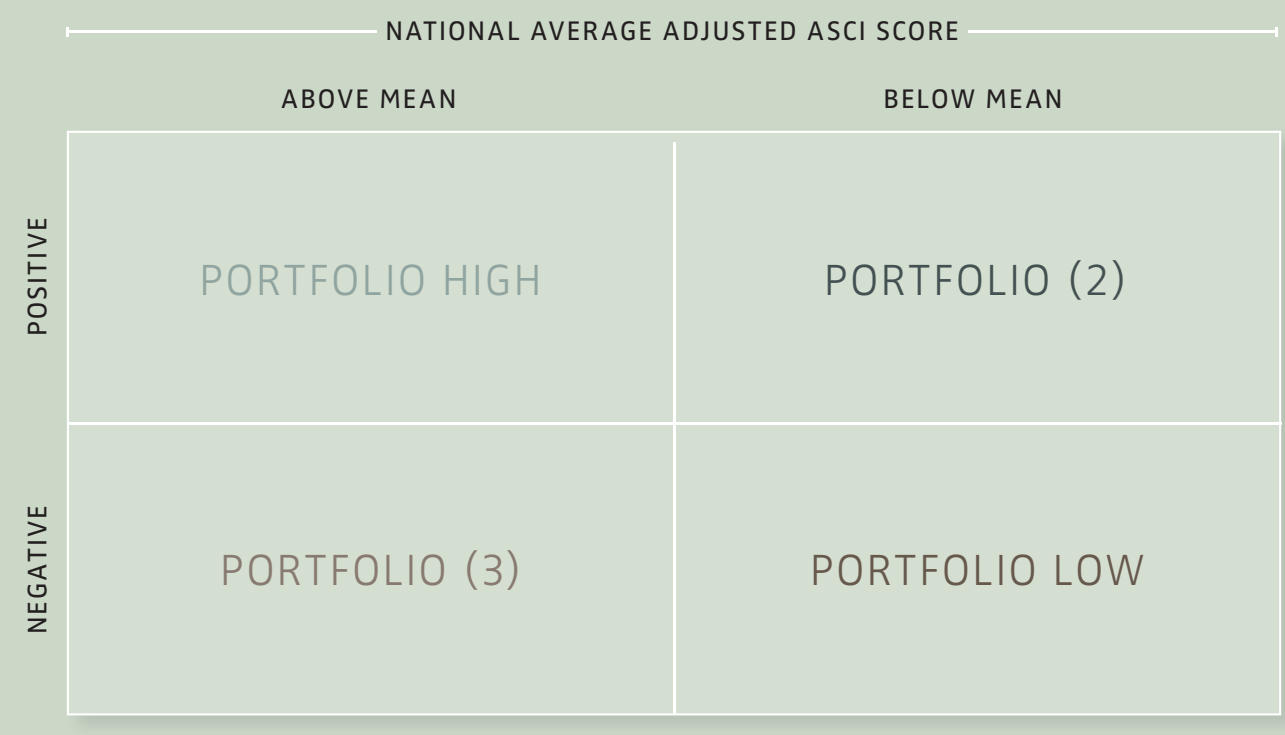

FIGURE 1

Portfolio Formation

\section{FIGURE 2}

Customer Satisfaction and Cumulative Portfolio Returns

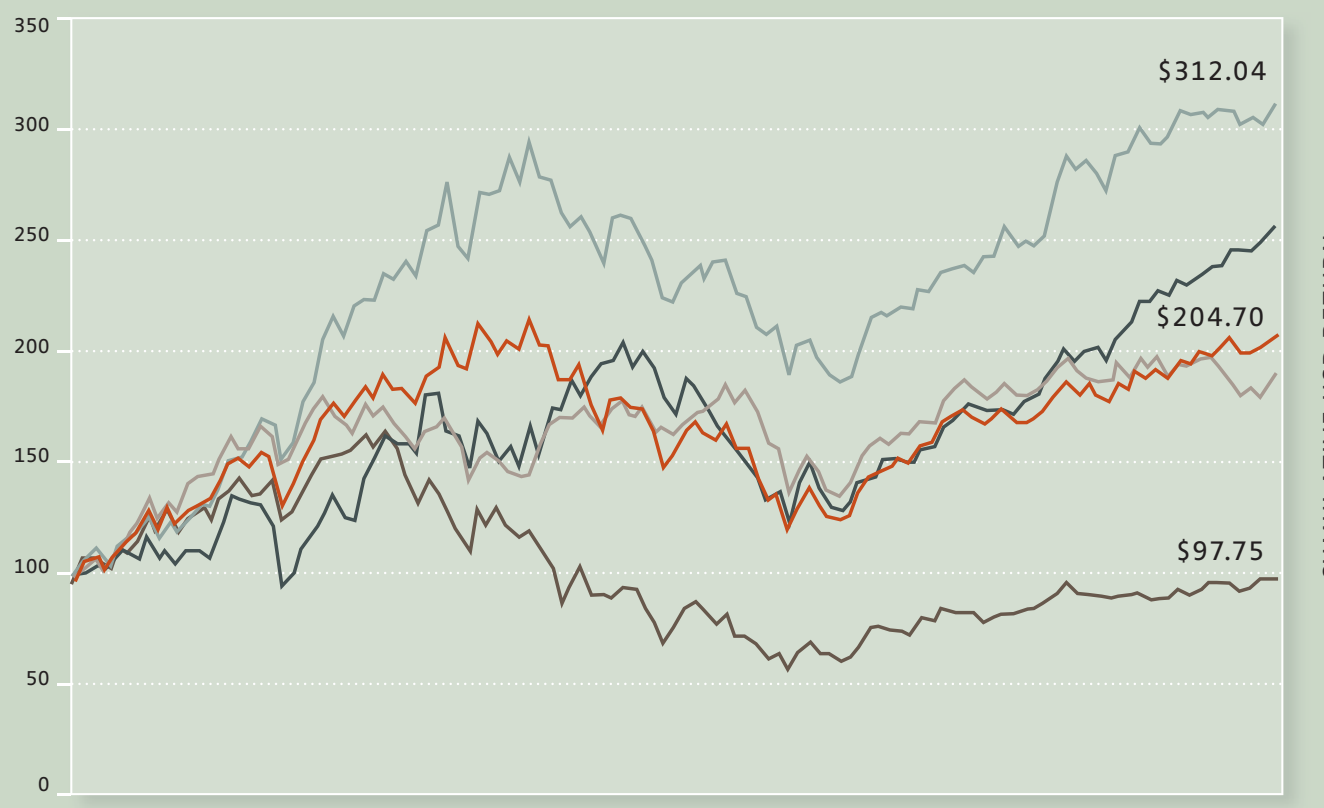

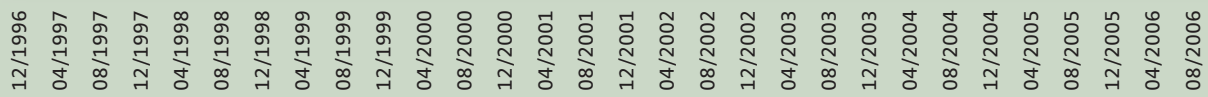
MONTH

$\begin{array}{llllll}\text { High } & 2 \\ & 3 & \end{array}$




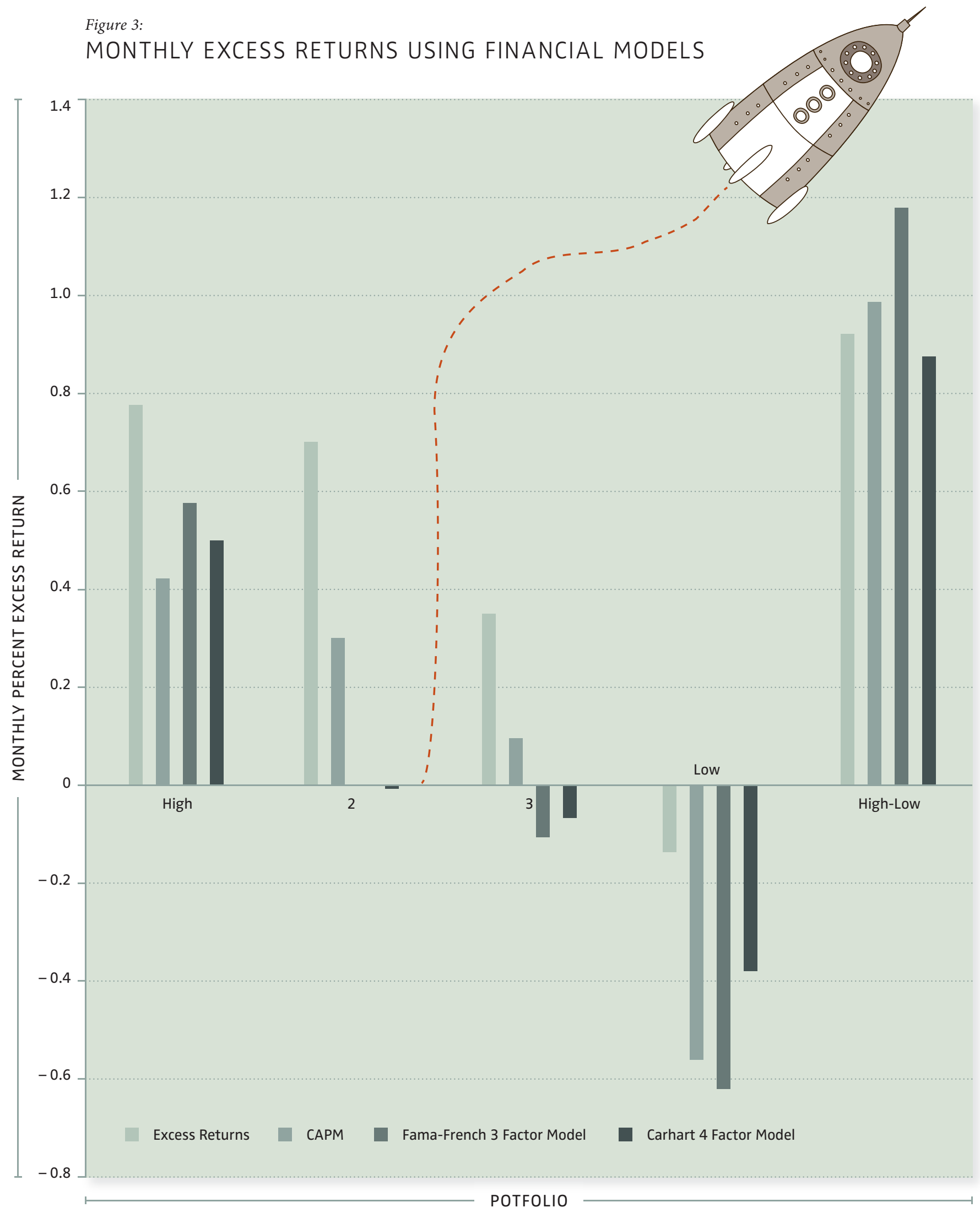


Fama and French argue that a three-factor model which incorporates size, value, and the market factors can explain almost all pricing anomalies.

The final model used to estimate abnormal portfolio returns is the Fama French (Carhart) 4 Factor Model. In addition to the variables in the Fama French 3 Factor Model, a momentum variable is included as an additional risk factor. This risk factor accounts for the popularity of the stock in the market.

Running these models on the data indicate striking results in terms of the impact of high levels and positive changes in customer satisfaction over time. If one is to invest in Portfolio High, it would bring a clear positive excess return of $0.78 \%$ per month above and beyond the risk factors!

Furthermore, the maximum gains would be achieved by following an investment strategy where one would build a zero net-investment portfolio. This would imply buying stocks in Portfolio High and short selling those in Portfolio Low (High-Low). Based on this investment strategy it is possible to make an average monthly excess return of $0.92 \%$.

As Figure 3 indicates, monthly abnormal returns for the various portfolios are quite varied with the highest gain from Portfolio High and negative returns from Portfolio Low. The other portfolios are somewhere in between. The results are clearly quite consistent across the 3 different financial models used. When we examine the zero net investment portfolio based on the Fama French (Carhart) 4 Factor Model for example, the results indicates an abnormal return (risk-adjusted) of $0.88 \%$ per month. This is a sizeable gain which adds up to a significant $10.56 \%$ per year even after controlling for risk! The only risk factor that is significant in this portfolio is a momentum effect present in stock returns. Portfolio High tends to have in-favor stocks whereas Portfolio low tends to have stocks that are mostly out-of-favor with investors.

In summary, these results provide strong evidence that high and increasing customer satisfaction leads to abnormally high stock returns, indicating that the stock market is slow to recognize the full extent of the intangible value created (Refer to Figure 3 ).

What did experts in the area of finance have to say? Personal interviews that we conducted with senior executives of one of the largest institutional securities firms pointed to the need to conduct rigorous testing of multiple start-end dates (referred to in the industry as "backtesting") for the portfolios we formed. Specifically, analysts wanted to see "a rigorous and realistic backtest of the investment hypothesis, which should include periods of adverse investment environments, may provide some confidence in the potential performance of the investment process. Finally, a detailed performance and risk attribution analysis is critical to identifying the degree of insight in the specific investment hypothesis".

To address these concerns of the finance community, we calculated the returns of each portfolio and the S\&P 500 for various holding periods from a one-quarter minimum holding period to a seven-year minimum holding period. At the end of each end date, each portfolio is assigned a finishing position from first to fifth place. Consistently Portfolio High finishes first place in terms of performance regardless of the start and end date of portfolio formation.

Furthermore, the state of the economy also has the potential to affect company valuations. A weakening of the economy, as indicated by the National Activity Index (NAI) for example, can result in a negatively impacted earnings growth and vice versa. To test the performance of the portfolios across different states of the economy, we divided the data in two based on whether the average NAl is positive (economy expanding above average) or negative (economy expanding below average). The results indicate that in general the results found earlier remain consistent despite changes in economic performance. In fact, the findings suggest that firms with high and increasing customer satisfaction can leverage this resource to provide larger returns to shareholders in periods of economic expansion. In addition, there is some indication that the value of having highly satisfied customers might dampen the negative impact of an overall economic downturn.

\section{What Does All This Mean for Managers?}

The bottom line is that creating customer satisfaction does matter! And intangible assets such as this measure of customer equity can yield valuable information in addition to traditional tangible asset metrics.

We demonstrate that investing in a portfolio of firms with high and increasing customer satisfaction is far superior to investing in a portfolio of firms with low and decreasing customer satisfaction. This strategy beat the market, far outperforming the S\&P 500 index. 
\{Insert $\}$

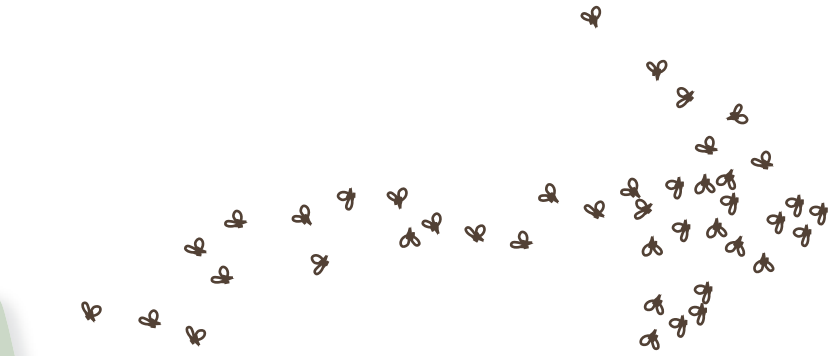

\& वी

a

of

\section{ACSI (The American Customer Satisfaction Index)}

ACSI reports scores on a $0-100$ scale at the national level and produces indexes for 10 economic sectors, 44 industries (including e-commerce and e-business), and more than 200 companies and federal or local government agencies. In addition to the company-level satisfaction scores, ACSI produces scores for the causes and consequences of customer satisfaction and their relationships. The measured companies, industries, and sectors are broadly representative of the U.S. economy serving American households.

The American Customer Satisfaction Index uses customer interviews as input to a multi-equation econometric model developed at the University of Michigan's Ross School of Business. The ACSI model is a cause-andeffect model with indices for drivers of satisfaction on the left side (customer expectations, perceived quality, and perceived value), satisfaction (ACSI) in the center, and outcomes of satisfaction on the right side (customer complaints and customer loyalty, including customer retention and price tolerance).
The indexes (shown in the diagram below) are multivariable components measured by several questions that are weighted within the model. The questions assess customer evaluations of the determinants of each index. Indexes are reported on a 0 to 100 scale. The survey and modeling methodology quantifies the strength of the effect of the index on the left to the one to which the arrow points on the right. These arrows represent "impacts". The ACSI model is self-weighting to maximize the explanation of customer satisfaction (ACSI) on customer loyalty. Looking at the indexes and impacts, users can determine which drivers of satisfaction, if improved, would have the most effect on customer loyalty.

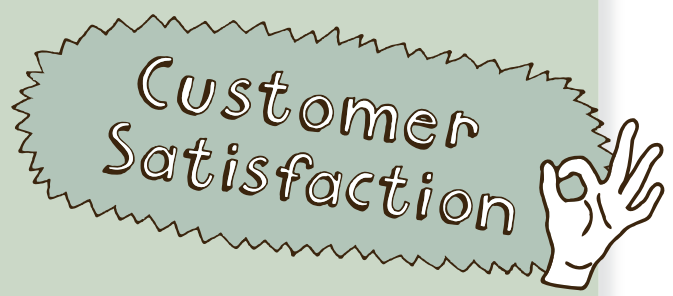

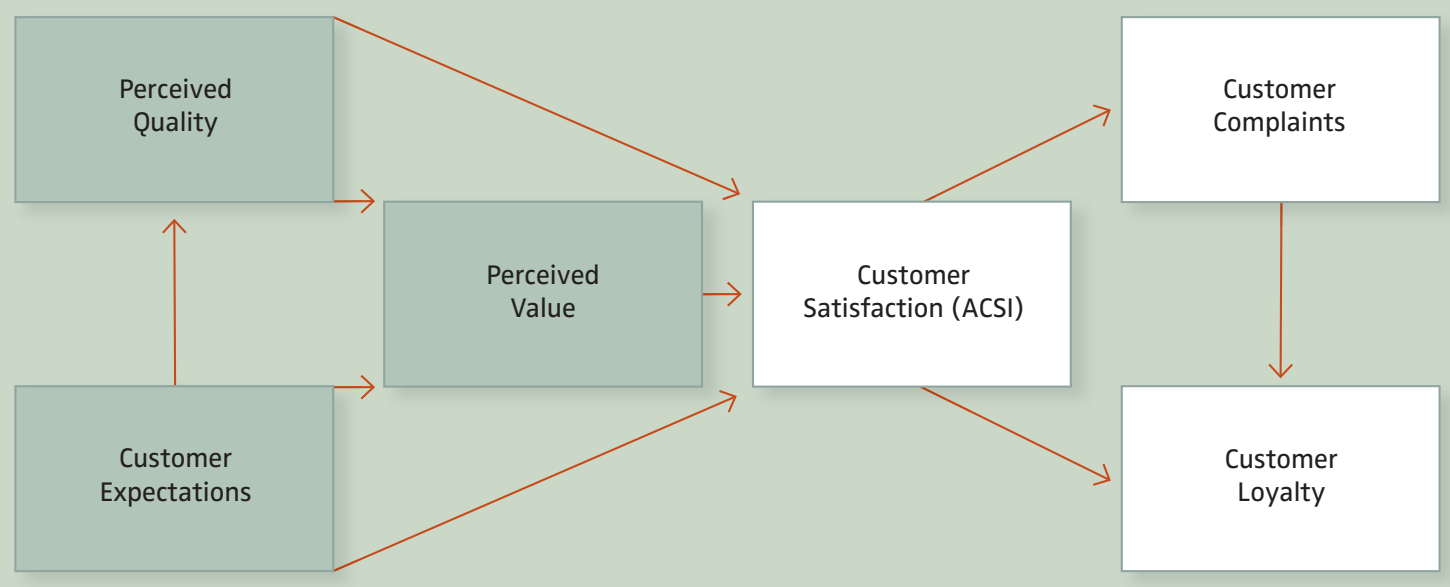

Source: $w w w$.theacsi.org 


\section{FURTHER READING}

Given that riskier portfolio strategies invariably bring with it higher potential returns, there was a need to adjust for risk factors by using models such as the CAPM Fama French 3 Factor Model, and Carhart 4 Factor Models. The results indicate the only significant risk factor to be momentum (winner/loser effect). High customer satisfaction portfolios tend to have more in-favor stocks, and low-customer-satisfaction portfolios tend to have more out-of-favor stocks. Therefore, it turns out that even after we adjust for relevant risk factors, the results indicate a positive risk-adjusted return for a high customer satisfaction portfolio that can add up to over $10 \%$ return a year!

We also find that the intangible value created by high customer satisfaction is more likely to be undervalued by Wall Street immediately following customer satisfaction information announcements made. Even though the market initially undervalues positive customer satisfaction information, it adjusts over time.

These results have important implications for research analysts and portfolio managers alike. Customer satisfaction is found to have an important influence on firm value and thus can be used actively in portfolio strategies to generate superior returns. Forming portfolios on the basis of satisfaction data, especially when such data are publicly available, has the potential to generate valuable excess returns.

One of the frequent criticisms of and skepticism towards marketing is its perceived inability to quantify its value added to business. Due to this lack of accountability, expenditures in increasing customer satisfaction are deemed unnecessary or even useless. This research however clearly demonstrates the superior returns to shareholders that investments in customer satisfaction can provide. •
American Customer Satisfaction Index:

http://www.theacsi.org

Fornell, Claes, Sunil Mithas, Forest V. Morgenson III, and M.S. Krishan (2006),

"Customer Satisfaction and Stock Prices: High Returns, Low Risk", Journal of Marketing, 70 (January),

pp. $1-14$.

Gruca, Thomas S. and Lopo L. Rego (2005),

"Customer Satisfaction, Cash Flow, and Shareholder Value", Journal of Marketing, 69 (July),

pp. $115-30$.

Anderson, Eugene W., Claes Fornell, and Sanal K.

Mazvancheryl (2004),

"Customer Satisfaction and Shareholder Value", Journal of Marketing, 68 (October),

pp. $172-85$.

KEYWORDS:

Customer Satisfaction,

Firm Value,

Marketing Metrics 